\title{
Prevalence and Economic Impact of Acute Myocardial Infarction in the Brazilian Public Health System: Care and Economic Analysis and the Impacts of the Coronavirus Disease
}

June Alisson Westarb Cruz ( $\sim$ june.cruz@pucpr.br)

Getúlio Vargas Foundation - EAESP

Gustavo Martini Buso

Pontifical Catholic University of Paraná

Lidia Ana Zytynski Moura

Pontifical Catholic University of Paraná

Maria Alexandra Viegas Cortez da Cunha

Getúlio Vargas Foundation - EAESP

Tiago Zequinão

Laboratory of Emerging Infectious Diseases, School of Medicine PUCPR

Kleberson Massaro Rodrigues

Higher Institute of Administration and Economics - ISAE FGV

Felipe Francisco Tuon

Pontifícia Universidade Católica do Paraná

Thyago Proença de Moraes

Pontifícia Universidade Católica do Paraná

\section{Sandro Marques}

Pontifical Catholic University of Paraná

\section{Research Article}

Keywords: public health system, acute myocardial infarction, cardiology, COVID-19

Posted Date: November 15th, 2021

DOI: https://doi.org/10.21203/rs.3.rs-984298/v1

License: (1) This work is licensed under a Creative Commons Attribution 4.0 International License. Read Full License 


\section{Abstract \\ Background}

This study aimed to describe the general and specific context of hospitalizations for acute myocardial infarction (IAM) in the Brazilian public health system and its main indicators of economic care in the preand post-coronavirus-disease (COVID-19) period.

\section{Methods}

The main assistance and economic indicators of care related to IAM, together with the Brazilian public health system, were evaluated in the period between January 2011 and April 2021, comparing the preand post-pandemic indicators. The research figures were descriptive and exploratory, using data from the Ministry of Health. The main data evaluated were lethality, number of hospitalizations, average length of hospital stay, and hospitalization costs. The ARIMA and general regression models were used to analyze the monthly outcomes pre and post COVID-19, thus enabling the alteration of care and economic behavior of IAM cases with the public health system.

\section{Results}

Hospitalization for IAM has been on the rise for the past 10 years, with a slight decrease after COVID-19. There was an equally slight increase in lethality, with a significant decrease in the mean length of stay of hospitalized patients. The economic aspects of IAM show that more than US\$ 762 million were invested during the reporting period. The average ticket presents a clear decrease in investment per capita, with a real devaluation of $70.04 \%$ in the period from 2011 to April 2021, which may be related to two main hypotheses: (1) increased effectiveness and (2) cost analysis of the effectiveness of care and/or chronic underfunding of the Brazilian public health system.

\section{Conclusions}

There was a historical increase in hospitalizations and a reduction in IAM-related deaths.

\section{Introduction}

Brazil covers a surface area of 8.5 million $\mathrm{km}^{2}$ and has a population of approximately 211 million people. ${ }^{1,2}$ Its health system comprises the state segment implemented through the Unified Health System (SUS) and the private sector. ${ }^{3}$ Created in $1988,{ }^{5}$ with constitutional provision, the SUS serves approximately $76 \%$ of the Brazilian population, 7,10 which, despite its historical achievement in coverage and access, suffers strongly due to chronic underfunding. ${ }^{4,6}$ Currently, the Unified Health System has 
5,161 general hospitals, ${ }^{8,9} 1,045$ specialized hospitals, ${ }^{8}$ and 9,935 basic health units, ${ }^{13}$ thus covering 239,329 clinical beds, ${ }^{13} 204,874$ surgical beds, ${ }^{13}$ and 514,004 medical professionals. ${ }^{13}$

The country faces great challenges in the field of health care, ${ }^{4}$ partially because of the intense socioeconomic inequality (Gini Index, 50.9) ${ }^{5,6}$ In this context, cardiology has a high prevalence of care in SUS. The specialty, together with SUS, has a total of 15,624 cardiologists and 1,147 cardiovascular surgeons, 4,583 clinical beds, and 3,091 surgical beds, and it performed over 115,299,459 hospitalizations (from January 2011 to April 2021), of which 1,087,901 were linked to acute myocardial infarction (IAM) ${ }^{13}$

In this context, the central objective of this research was to understand the specific context of IAM with the Brazilian public health system and its main indicators of assistance and economics, as well as the impact of COVID-19.

\section{Methods}

This descriptive and exploratory study used secondary data from the following official sources: TAbnet, ${ }^{13}$ IBGE, ${ }^{1,21}$ IPEADATA, ${ }^{2}$ Anahp, ${ }^{9}$ Agência Nacional de Saúde, ${ }^{10}$ and Trading Economics. ${ }^{11}$ Data were subjected to quantitative analysis. In addition, this study examined the history of IAM in the Brazilian public health system during the last decade.

A descriptive statistical analysis was performed, which allowed us to understand the historical series of evolution of cardiology, more specifically IAM, highlighting for each of the states of the Federation, from January 2011 to April 2021, the following: lethality, number of hospitalizations, average hospital stay rate, average ticket paid by SUS, and total payments.

The analysis of the average ticket was performed considering its nominal value, and it was corrected by the General Index of Brazilian Consumer Prices in Health (IPCA-Health), ${ }^{2}$ thus enabling the comparison of not only the historical series in its value, but also its ability to convert into value over time.

Following the experience of research carried out in cardiology, ${ }^{22}$ para the comparative analysis between the pre-and post-COVID-19 periods and for the analysis of interrupted time series, data were summable, disregarding the Federative Unit, and demonstrated as monthly measures. Monthly hospitalizations were relativized by 100,000 inhabitants in Brazil. The permanence data represent a monthly average on days when the patient remained hospitalized; the lethality rate represents the monthly average of deaths by active patients; and the average monthly ticket, which portrays the financial value (in dollars) received by hospitals for each hospitalization related to heart failure.

An analysis of interrupted time series (STI) was performed to estimate the changes in the levels and trends of the variables studied, caused by the emergence of coronavirus at the national level. The cut-off point was defined in the months of March-April 2020, separating previous data from the pre-COVID-19 
period, and the subsequent data from the COVID-19 period. The ARIMA method was used to model the time series. The overall regression model for analyzing outcomes monthly can be described as

$Y t=\beta 0+\beta 1 T+\beta 2 X t+\beta 3 T X t$

where $\beta 0$ is the initial level when $T=0, \beta 1$ is the tendency of the outcome related to the increase of the time units, $\beta 2$ corresponds to the change in level after the beginning of the pandemic, and $\beta 3$ indicates the change in the monthly trend. Descriptive analyses of the variables, normality tests, and comparisons between periods with the Student or Mann-Whitney tests were also performed, according to the distribution of the variables. The analyses were performed using the SPSS 25.0 program, and the graphs were elaborated in Microsoft Excel. Statistical significance for all tests was defined as a $p$-value $<0.05$.

\section{Results}

\section{Descriptive analysis: Hospitalization, permanence, lethality, and expenses.}

The IAM showed a significant increase in the number of hospitalizations in the last decade, with stability from the advent of the pandemic. As noted in Table 1, in 2011, a total of 81,446 hospitalizations were recorded nationwide, increasing to 132,614 in 2019. More specifically, in 2020, reaching 129,710 cases with a downward trend curve for 2021, which until April had a total of 30,737 cases, with a monthly average of 7,684 cases, $28.91 \%$ lower than the monthly average of 2020 .

Observing the nominal values in relation to the population, there was an increase of 41.43 cases per 100,000 inhabitants in 2011 to 61.26 cases per 100,000 inhabitants in 2020, making a significant increase of $47.86 \%$ (Table 1 ). 
Table 1

Historical series of IAM hospitalizations from 2011 to 2020 for every 100,000 inhabitants

\begin{tabular}{|lllll|}
\hline Year & Admissions & Population & Percentage (\%) & 100 Habits \\
\hline 2011 & 81,446 & $196,589,921$ & $0.04 \%$ & 41.43 \\
\hline 2012 & 85,309 & $198,310,734$ & $0.04 \%$ & 43.02 \\
\hline 2013 & 87,462 & $200,033,072$ & $0.04 \%$ & 43.72 \\
\hline 2014 & 96,068 & $201,752,062$ & $0.05 \%$ & 47.62 \\
\hline 2015 & 101,539 & $203,462,824$ & $0.05 \%$ & 49.91 \\
\hline 2016 & 108,527 & $205,160,483$ & $0.05 \%$ & 52.90 \\
\hline 2017 & 114,053 & $206,840,164$ & $0.06 \%$ & 55.14 \\
\hline 2018 & 120,436 & $208,496,988$ & $0.06 \%$ & 57.76 \\
\hline 2019 & 132,614 & $210,126,079$ & $0.06 \%$ & 63.11 \\
\hline 2020 & 129,710 & $211,722,560$ & $0.06 \%$ & 61.26 \\
\hline
\end{tabular}

Observing the historical series of IAM hospitalizations by state of the Brazilian federation, the general behavior of Brazil was repeated in all regions, without exceptions, thus demonstrating the evident increase in prevalence, considering the data presented in Figure 1.

Although the history of hospitalizations from IAM with the Brazilian Unified Health System shows a significant increase, the rate of permanence of hospitalized patients is within a range of little elasticity. As shown in Graph 2, in 2011, the rate of permanence of hospitalized patients with IAM was 6.72 days on average, reaching a period of 7.60 days in 2018 , with a decrease from 2020 , which has an average of 6.92 days, and 5.51 in 2021 (data until April).

When observing this historical series of permanence by the states of Brazilian Federation, the general data for the country are presented differently across the states. Thus, Mato Grosso do Sul, Paraná, Roraima, and Sergipe are increasing throughout the study period. All other states follow the national trend and show a reduction in the length of stay from 2020 to 2021. Table 2 presents in blue the periods of increasing permanence, and in yellow, the periods of decreasing permanence. 
Table 2

Historical series of average rate of IAM permanence by states of the Federation from 2011 to April 2021

\begin{tabular}{|llllll|}
\hline States & $\mathbf{2 0 1 1}$ & $\mathbf{2 0 1 5}$ & $\mathbf{2 0 1 9}$ & $\mathbf{2 0 2 0}$ & *2021 \\
\hline Acre & 7.22 & 11.86 & 9.51 & 7.38 & 6.65 \\
\hline Alagoas & 6.54 & 7.25 & 8.76 & 9.37 & 6.80 \\
\hline Amapá & 8.43 & 8.52 & 8.31 & 8.38 & 3.65 \\
\hline Amazon & 8.54 & 10.83 & 11.57 & 10.90 & 9.66 \\
\hline Bahia & 8.77 & 9.95 & 8.66 & 8.29 & 7.03 \\
\hline Ceará & 6.97 & 8.35 & 8.25 & 10.48 & 7.89 \\
\hline Federal District & 16.70 & 11.87 & 12.24 & 14.20 & 10.78 \\
\hline Holy Spirit & 7.82 & 7.90 & 7.77 & 5.91 & 4.66 \\
\hline Goias & 4.34 & 4.51 & 4.84 & 5.47 & 4.75 \\
\hline Marana & 4.79 & 9.10 & 11.35 & 10.86 & 8.23 \\
\hline Mato Grosso & 6.13 & 7.92 & 6.40 & 6.28 & 5.24 \\
\hline Mato Grosso do Sul & 4.67 & 5.00 & 5.87 & 6.30 & 6.58 \\
\hline Minas Gerais & 6.59 & 6.59 & 7.27 & 7.03 & 5.98 \\
\hline Stop & 6.01 & 6.94 & 7.23 & 8.55 & 3.85 \\
\hline Paraiba & 4.60 & 4.35 & 6.02 & 7.08 & 5.60 \\
\hline Paraná & 4.36 & 4.72 & 5.08 & 4.94 & 5.46 \\
\hline Pernambuco & 7.73 & 9.52 & 11.11 & 10.09 & 10.50 \\
\hline Piaui & 4.44 & 6.45 & 6.55 & 4.10 & 2.00 \\
\hline Rio de Janeiro & 9.76 & 12.25 & 13.26 & 11.60 & 8.85 \\
\hline Rio Grande do Norte & 8.21 & 9.48 & 10.25 & 8.52 & 7.74 \\
\hline Rio Grande do Sul & 6.40 & 6.98 & 7.75 & 7.56 & 6.80 \\
\hline Rondonia & 4.80 & 6.95 & 9.42 & 9.63 & 7.49 \\
\hline Roraima & 7.17 & 7.95 & 10.22 & 12.25 & 12.76 \\
\hline Santa Catarina & 6.90 & 8.08 & 6.60 & 8.24 & 5.40 \\
\hline Sao Paulo & 9.13 & 9.63 & 9.49 & 8.84 & 7.43 \\
\hline
\end{tabular}




\begin{tabular}{|lccccc|}
\hline States & $\mathbf{2 0 1 1}$ & $\mathbf{2 0 1 5}$ & $\mathbf{2 0 1 9}$ & $\mathbf{2 0 2 0}$ & *2021 \\
\hline Sergipe & 5.33 & 6.70 & 10.38 & 10.77 & 11.31 \\
\hline Tocantins & 5.24 & 5.68 & 6.13 & 5.62 & 2.10 \\
\hline \multicolumn{7}{|l}{ * Corresponding to data until April 2021} & & & \\
\hline
\end{tabular}

Among the probable explanations of the relevant differences between the states of the Brazilian Federation, the structural differences in resources for health care and care protocols represent the central hypothesis. $^{12}$

Regarding the IAM lethality, COVID-19 promoted a significant increase in mortality worldwide, ${ }^{15}$ in addition to the increase of deaths from the pandemic, several countries also observed a significant increase in deaths from cardiovascular diseases. ${ }^{15}$ The lethality of IAM decreased from 2011 (14.77\%) to 2019 (10.69\%), with percentage stability in 2020 (10.69\%) and a small increase in 2021 (January to April: $11.15 \%)$. Among the probable hypotheses, the historical decrease followed by stability and the small post-COVID-19 increase, it is possible to highlight the decrease or delay of the population's demand for assistance in cases of lower severity, as well as the dedicated allocation of health structures for exclusively COVID-19 cases in 2020 and 2021. Graph 3 shows the historical series of IAM mortality rates from 2011 to April 2021.

When observing this historical series of the IAM mortality rate, one can notice a historical decrease in lethality in almost all states from 2011 to 2019, except for Ceará, Maranhão, and Paraíba. By descriptively analyzing the pre- and post-COVID-19 period, it is possible to identify that most states, following national trends, had a small worsening of lethality from 2020 , whose statistical analysis is presented in the article. The state-specific data are shown in Table 3. 
Table 3

Historical series of IAM lethality rate by states of the Federation from 2011 to April 2021

\begin{tabular}{|llllll|}
\hline States & $\mathbf{2 0 1 1}$ & $\mathbf{2 0 1 5}$ & $\mathbf{2 0 1 9}$ & $\mathbf{2 0 2 0}$ & \multirow{2}{*}{$\mathbf{2 0 2 1}$} \\
\hline Acre & $27.70 \%$ & $22.75 \%$ & $19.67 \%$ & $15.78 \%$ & $30.36 \%$ \\
\hline Alagoas & $19.62 \%$ & $17.13 \%$ & $16.01 \%$ & $13.41 \%$ & $19.81 \%$ \\
\hline Amapá & $6.19 \%$ & $17.69 \%$ & $9.77 \%$ & $14.79 \%$ & $6.67 \%$ \\
\hline Amazon & $10.72 \%$ & $10.41 \%$ & $10.51 \%$ & $12.57 \%$ & $7.00 \%$ \\
\hline Bahia & $13.81 \%$ & $12.23 \%$ & $10.59 \%$ & $11.30 \%$ & $10.82 \%$ \\
\hline Ceará & $10.26 \%$ & $12.73 \%$ & $13.67 \%$ & $13.69 \%$ & $11.21 \%$ \\
\hline Federal District & $9.84 \%$ & $11.78 \%$ & $3.58 \%$ & $3.42 \%$ & $4.04 \%$ \\
\hline Holy Spirit & $12.84 \%$ & $8.57 \%$ & $5.60 \%$ & $7.17 \%$ & $5.95 \%$ \\
\hline Goias & $11.97 \%$ & $11.98 \%$ & $8.92 \%$ & $8.12 \%$ & $7.26 \%$ \\
\hline Maranhao & $13.08 \%$ & $15.32 \%$ & $12.15 \%$ & $15.24 \%$ & $16.60 \%$ \\
\hline Mato Grosso & $19.81 \%$ & $13.96 \%$ & $10.67 \%$ & $8.73 \%$ & $8.67 \%$ \\
\hline Mato Grosso do Sul & $14.62 \%$ & $13.33 \%$ & $11.71 \%$ & $9.43 \%$ & $11.76 \%$ \\
\hline Minas Gerais & $10.20 \%$ & $9.32 \%$ & $8.11 \%$ & $8.16 \%$ & $7.55 \%$ \\
\hline Stop & $16.81 \%$ & $14.23 \%$ & $12.02 \%$ & $10.18 \%$ & $11.16 \%$ \\
\hline Paraiba & $18.36 \%$ & $8.32 \%$ & $11.51 \%$ & $20.27 \%$ & $17.35 \%$ \\
\hline Paraná & $13.47 \%$ & $13.17 \%$ & $10.93 \%$ & $11.26 \%$ & $10.55 \%$ \\
\hline Pernambuco & $12.00 \%$ & $10.24 \%$ & $9.91 \%$ & $9.81 \%$ & $10.88 \%$ \\
\hline Piaui & $14.53 \%$ & $9.29 \%$ & $7.17 \%$ & $6.47 \%$ & $4.94 \%$ \\
\hline Rio de Janeiro & $14.05 \%$ & $15.06 \%$ & $12.28 \%$ & $11.86 \%$ & $13.47 \%$ \\
\hline Rio Grande do Norte & $15.82 \%$ & $13.36 \%$ & $9.65 \%$ & $8.47 \%$ & $9.70 \%$ \\
\hline Rio Grande do Sul & $11.24 \%$ & $10.20 \%$ & $8.45 \%$ & $7.50 \%$ & $8.97 \%$ \\
\hline Rondonia & $20.84 \%$ & $15.71 \%$ & $10.85 \%$ & $10.53 \%$ & $8.81 \%$ \\
\hline Roraima & $24.91 \%$ & $13.91 \%$ & $12.41 \%$ & $8.99 \%$ & $15.03 \%$ \\
\hline Santa Catarina & $10.37 \%$ & $9.23 \%$ & $8.62 \%$ & $8.69 \%$ & $10.59 \%$ \\
\hline Sao Paulo & $13.10 \%$ & $11.85 \%$ & $9.54 \%$ & $9.69 \%$ & $9.31 \%$ \\
\hline
\end{tabular}




\begin{tabular}{|llllll|}
\hline States & $\mathbf{2 0 1 1}$ & $\mathbf{2 0 1 5}$ & $\mathbf{2 0 1 9}$ & $\mathbf{2 0 2 0}$ & *2021 \\
\hline Sergipe & $16.64 \%$ & $14.16 \%$ & $12.15 \%$ & $10.67 \%$ & $15.25 \%$ \\
\hline Tocantins & $15.82 \%$ & $12.80 \%$ & $12.09 \%$ & $12.56 \%$ & $7.31 \%$ \\
\hline \multicolumn{2}{|l}{ * Corresponding to data until April } & & & \\
\hline
\end{tabular}

Regarding the amounts spent by public health, in the period from January 2011 to April 2021, there was a total sum of over 762 million dollars, ${ }^{11,13}$ of which $12.04 \%$ were allocated to elective cases and $87.96 \%$ to cases classified as urgency or emergency. The amounts allocated for IAM can be considered relevant to the reality of public health in the country. Graph 4 thus shows the historical series of the amounts spent on IAM in the Brazilian public health year by year.

During this period, the average payment ticket for IAM went from US\$ 598.78 in 2011 to US\$ 707.05 in 2021 , representing a nominal growth of $18.08 \%$. The average period ticket is shown in Graph 5 .

If we consider the health price adjustment index in the Brazilian market (IPCA Saúde) during the same period, there is an adjustment of $88.12 \%, 2,11$ as shown in Graph 6 .

When relating the average ticket to the Health IPCA during the same period, it is observed that although in nominal terms, the average ticket represents an increase of $18.08 \%$, in real terms, when considering the price adjustment indexes of the same period, there is a relevant reduction of $70.04 \%$ in the average ticket of IAM visits from 2011 to April 2021. This percentage mismatch in time can be explained by two main hypotheses: the first and most likely is due to the chronic sub-financing of the Brazilian health system, ${ }^{4}$ the focus of many markets research analysis;;, ${ }^{62}$ the second is due to the improvement of care conditions, technologies, and care protocols.

\section{COVID-19 impact analysis}

To analyze the impact of COVID-19 on IAM, a total of 124 months from January 2011 to April 2021 were analyzed. The initial 111 months were considered as the pre-COVID-19 period, from January 2011 to March 2020, and 13 months later as the COVID-19 period, from April 2020 to April 2021.

Hospitalizations per 100,000 inhabitants had a median of 92.45 (77.68-106.98) monthly hospitalizations, with a minimum value of 36.72 in April 2021, and a maximum of 129.54 in July 2019. In the comparison between the periods, there was a historical increase in hospitalizations until 2020 (Table 1). In the analysis of ITS, the trend of hospitalizations in the pre-COVID-19 period was in an increasing curve of $0.519(p<0.001)$ monthly hospitalizations, which underwent a trend change of $-4.648(p<$ 0.001) after the beginning of the COVID-19 period, as observed in Tables 2 and 3 and Figure 2, evidencing, therefore, that IAM in attention to COVID-19 generated a decrease in IAM hospitalizations, in relation to the growth trend of cases before the pandemic. 
Table 4

Comparison between the periods

\begin{tabular}{|llll|}
\hline & $\begin{array}{l}\text { Pre-COVID-19 Period (SD, } \\
\text { IQR) }\end{array}$ & $\begin{array}{l}\text { COVID-19 period (SD, } \\
\text { IQR) }\end{array}$ & $\begin{array}{l}\text { p- } \\
\text { value }\end{array}$ \\
\hline $\begin{array}{l}\text { Admissions per 100,000 } \\
\text { inhabitants }\end{array}$ & $91.09(77.40-106.56)$ & $109.17(94.11-118.32)$ & 0.04 \\
\hline Length of stay (days) & $7.20(0.54)$ & $6.40(1.14)$ & 0.03 \\
\hline Lethality rate (\%) & $12.69(1.71)$ & $11.02(1.78)$ & 0.001 \\
\hline Average Ticket & $450.30(380.17-514.74)$ & $500.70(464.44-583.51)$ & 0.01 \\
\hline SD. Standard deviation; IQR. Interquartile range. & & \\
\hline
\end{tabular}

The mean length of stay due to IAM throughout the period was 7.11 (DS; 0.67) days, with a minimum value of 3.54 days in April 2021, and a maximum value of 8.83 days in August 2018. The mean length of stay was reduced by $0.80(p=0.03)$ when comparing the COVID-19 period with the pre-COVID-19 period (Table 4). In the initial period, the average length of stay was 6.78 days with a monthly increase trend of 0.007 days $(p=0.001)$. After the beginning of the COVID-19 period, there was a change in the trend, resulting in a negative slope of $-0.157(p=0.005)$ (Table 5).

Table 5

Interrupted time series analysis.

\begin{tabular}{|c|c|c|c|c|c|c|c|}
\hline & $\begin{array}{l}\text { Pre-COVID-19 } \\
\text { Period } \\
\text { Coefficient }\end{array}$ & $\begin{array}{l}\text { Pre- } \\
\text { COVID-19 } \\
\text { Period } \\
\text { Slope }\end{array}$ & $p$-value & $\begin{array}{l}\text { Level } \\
\text { Change }\end{array}$ & $p$-value & $\begin{array}{l}\text { Slope } \\
\text { Change }\end{array}$ & $p$-value \\
\hline $\begin{array}{l}\text { Admissions per } \\
100,000 \\
\text { inhabitants }\end{array}$ & 64.52 & 0.519 & $<0.001$ & -9.228 & 0.155 & -4.648 & $<0.001$ \\
\hline $\begin{array}{l}\text { Lenght of stay } \\
\text { (days) }\end{array}$ & 6.78 & 0.007 & 0.001 & -0.387 & 0.337 & -0.157 & 0.005 \\
\hline $\begin{array}{l}\text { Lethality rate } \\
(\%)\end{array}$ & 14.87 & -0.039 & $<0.001$ & 1.445 & 0.062 & -0.097 & 0.343 \\
\hline $\begin{array}{l}\text { Average Ticket } \\
\text { (BRL) }\end{array}$ & 380.96 & 1.510 & 0.002 & -41.441 & 0.600 & -0.114 & 0.991 \\
\hline
\end{tabular}

The lethality rate averaged $12.49 \%$ (DS; 1.78 ) in the accumulated period, with the lowest value of $8.98 \%$ in September 2019 , and a higher value of $16.28 \%$ in June 2012 . The lethality rate decreased from $12.69-$ $11.02 \%$ compared to that during the pre-COVID-19 period (Table 3). In the STI analysis, the lethality rate 
suffered a monthly decrease of -0.039 percentage points from the beginning, remaining with a similar trend and throughout the period studied (Table 4); thus, there was no significant change in lethality, although the first four months of 2021 presented a small increase (Graph 3).

The average ticket exercised by the hospitals had a median of US\$ 457.23 (IQR: 387.30-525.46) during the study period. The lowest amount was US\$ 276.81 in December 2011, and the maximum amount was US\$ 906.17 in October 2018. The analysis did not demonstrate relevant impacts on this variable due to COVID-19, confirming the economic analyses already presented in the research.

Upper left graph. Monthly IAM admissions per 100,000 inhabitants. Upper right graph. Monthly mean length of stay in days. Lower left graph. Monthly percent IAM lethality rate. Lower right graph. Monthly average ticket in US\$ dollars

Open dots represent pre-COVID-19 period monthly data, and black solid dots represent the COVID-19 period. The dashed line illustrates monthly trends. The vertical solid line represents the time interruption between the periods.

\section{Discussion}

Health care is implemented through a complex system that combines economic elements and assistance in a single environment. ${ }^{6}$ In the Brazilian health system, these elements are operationalized through the public system ${ }^{17}$ and private sector, ${ }^{6}$ both with the challenge of providing access and quality in health care. $^{23}$

In Brazilian public health, challenges are aggravated by many circumstances, including economic and social inequality, geographical extension, regulation of the public sector, and public budget.

In this sense, describing and analyzing the history of IAM in the Brazilian public health system, as well as the impacts of COVID-19, can help guide the scenarios and trends of public assistance in the specialty of cardiology for the coming years, as well as in its economic and social impacts. ${ }^{24}$

In the national context, Brazilian cardiology represents $3.26 \%$ of the total number of physicians available in the country, ${ }^{13}$ with approximately $2.42 \%$ of the beds available, exclusive, and IAM is one of the pathologies showing great prevalence and economic representation in the specialty.

In general, the representativeness of the prevalence of cases with the Brazilian public system has increased in the past 10 years (increasing curve of $0.519 ; p<0.001$ ), which underwent a trend change of $-4.648(p<0.001)$ following the beginning of the pandemic.

Regarding the length of stay rate of the hospitalized patient, this indicator has little oscillation in the entire period studied, such as a small reduction of $0.80(p=0.03)$ days when comparing the COVID-19 period with the pre-COVID-19 period, resulting in a negative trend slope $(-0.157 ; p=0.005)$. 
The lethality of IAM decreased from 2011 to 2019, with a small increase during the first months of 2021, not presenting a significant change due to COVID-19. The analysis by states shows that most regions follow the national trend, with the exception of Ceará, Maranhão, and Paraíba, whose realities raise the importance of establishing specific public health strategies and policies, respecting regional particularities. $^{24}$

The investments made in Brazilian public health care for IAM care in the period analyzed totaled US\$ 762 million, predominantly destined for urgent and emergency cases (87.96\%). In this period, the average payment ticket for IAM had a nominal growth of $18.08 \%$, resulting in a displacement of $70.04 \%$ in relation to the main Brazilian price indicator (IPCA-Saúde), demonstrating strong evidence of chronic underfunding of the Brazilian public health system.

Regarding the advent of COVID-19, the historical increase in cases is clearly observable, without a statistically significant impact on COVID-19. Lethality, which until then was a historical trend of decrease, although presenting a small increase during the COVID-19 period, was not significant. The average rate of hospital stay showed a downward trend, with a negative inclination due to COVID-19. There is no direct relationship between the economic impacts of IAM and COVID-19.

Therefore, the conjuncture of analyses made from the data shows the care and economic importance of cardiology, more specifically IAM before the population using the Brazilian unified health system, which has a historical increase in hospitalizations, although a lower lethality rate, due to its increased prevalence, represents a higher number of deaths.

In a context where access to health is a major challenge, one should also pay attention to the aspect of the average rate of permanence, which until 2019 presented itself as an increasing trend curve. Another important aspect to consider is the economic aspects of IAM, as well as other pathologies ${ }^{16}$, are levant expenditure with the Brazilian public system ${ }^{14}$, which should be based on the improvement of the financing of complex specialties such as IAM, avoiding the scrap of health care, especially in more vulnerable regions. ${ }^{12}$

Finally, as a final consideration, the initiative to understand IAM health care in the Brazilian public context stands out, which purpose is to contribute to the access and qualification of health care, safeguarding premises of access to health, ${ }^{18}$ effectiveness, ${ }^{22}$ sustainability, ${ }^{6}$ cost effectiveness, ${ }^{16}$ quality, ${ }^{17}$ and humanization, ${ }^{20}$ highlighting the role of the state and organized civil society, in the improvement of governance tools that ensure the implementation of public policies in health, ${ }^{19}$ from an integrated vision, in the most diverse specialties, regions, and levels of care. ${ }^{21}$

\section{Declarations}

Ethics approval and consent to participate: Not applicable 
Availability of data and materials: Datasets generated and/or course during the current study are available in the files submitted to the journal.

Competing interests: None of the authors has conflicting interests.

Funding: Not applicable

Authors contributions: June Alisson Westarb Cruz, Lidia Ana Zytynski Moura, and Kleberson Massaro Rodrigues structured the text and established the relationship between the data and the theoretical approach, analyzed the practical impacts and suggestions of the research, and submitted the article to the journal; Gustavo Martini Buso, Tiago Zequinão and Sandro Marques organized the database, tables, graphs, and the article structure. Maria Alexandra Viegas Cortez da Cunha, Thyago Proença de Moraes and Felipe Francisco Tuon reviewed the coherence of the research, formatting, and made revisions of the English language and theoretical approaches to statistical analysis.

Acknowledgments: Not applicable

Data availability statement: All data generated or analysed during this study are included in this published article.

\section{References}

1. IBGE. 2021. https://www.ibge.gov.br. Accessed 10 July 2021.

2. IPEADATA. Data base Brazil. 2021. http://www.ipeadata.gov.br/Default.aspx. Accessed 17 July 2021.

3. Paim J, Travassos C, Almeida C, Bahia L, Macinko J. The Brazilian health system: history, advances, and challenges. Lancet, 377:1778-1797. 2011; doi:10.1016/S0140.

4. Rocha R, Atun R, Massuda A, Rache B, Spinola P, Nunes L, Lago M, Castro MC. Effect of socioeconomic inequalities and vulnerabilities on health-system preparedness and response to COVID-19 in Brazil: a comprehensive analysis. The Lancet. Global Health, 9:e782-e792. 2021; doi: 10.1016/S2214-109X(21)00081-4.

5. Castro MC, Massuda A, Almeida G, Menezes-Filho NA, Andrade MV, de Souza Noronha KVM, Rocha R, Macinko J, Hone T, Tasca R, Giovanella L, Malik AM, Werneck H, Fachini LA, Atun R. Brazil's unified health system: the first 30 years and prospects for the future. The Lancet, 394:345-356. 2019; doi: 10.1016/S0140-6736(19)31243-7.

6. Cruz JAW, Cunha MAVC, Moraes TP, Tuon FF, Linhares GP, Gomide AL, Marques S, Brazilian Private Health System. History, scenarios, and trends, PREPRINT. BMC Health Services Research. 2021; doi: 10.21203/rs.3.rs-726814/v1.

7. Batista AM, Cruz JAW, Piccoli PGR. Insolvency model applied to medical cooperative organizations: Brazilian market analysis. Management Magazine \& Cooperative Organizations. 2020; doi: $10.5902 / 2359043240561$. 
8. Brazilian federation of hospitals. Scenarios of hospitals in Brazil. 2020. https://www.fbh.com.br/wpcontent/uploads/2021/04/Cenarios_2020.pdf. Accessed 01 June 2021.

9. ANAHP. Sector analysis. 2021. https://www.anahp.com.br/dados-do-setor/. Accessed 01 August 2021.

10. National Agency for Supplementary Health. 2021. https://www.gov.br/ans/pt-br. Accessed 01 August 2021.

11. AGO. Trading economics. Data base Brazil. Accessed. 2021. https://pt.tradingeconomics.com/brazil/indicators 01.

12. Chaves VM, Zdziarski AD, Cruz JAW, Silva WV, Silva CL. Efficiency analysis of the unified health system service in Paraná municipalities. Journal of Globalization, Competitiveness \& Governability. 2017; doi: 10.3232/GCG.2017.V11.N2.02.

13. Brazil. Ministry of Health. SUS Date. Tabnet Health Information. 2021. http://www2.datasus.gov.br/DATASUS/index.php?area=02. Accessed 05 August 2021.

14. The Lancet. COVID-19 in Brazil: "So what?" In. Lancet, 395. 2020; doi: https://doi.org/10.1016/S0140-6736(20)31095-3.

15. Vieira JL, Sobral MGV, Florêncio RS, Alves VM, Vasconcelos GG, Almeida GPL, Marinho LLE, Fernandes JR, Mejia JAC, Neto JDS. Lessons learned by a multidisciplinary heart failure clinic in the midst of A pandemic. ABC Feart Failure \& Cardiomyopathy. 2021; doi: 10.36660/abchf.20210012.

16. Loesch GH, Cruz JAW, Gasparetto J, Oliveira DDS, Telles JP, Tuon FF. Cost minimization analysis of outpatient parenteral/oral antibiotic therapy at a trauma hospital: public health system. Infection Control \& Hospital Epidemiology:1-6. 2021; doi: 10.1017/ice.2021.22.

17. Gasparetto J, Tuon FF, Dos Santos Oliveira DS, Zequinão T, Pipolo GR, Ribeiro GV, Benincá PD, Cruz JAW, Moraes TP. Intravenous-to-oral antibiotic switch therapy: a cross-sectional study in critical care units. BMC Infectious Diseases, 19:650. 2019; doi: 10.1186/s12879-019-4280-0.

18. Moreno E, Vázquez-Polo FJ, Negrín-Henández MA. Cost-Effectiveness Analysis of Medical Treatments. Boca Raton: CRC Press. 2019.

19. Loesch G, Cruz JAW, Pecoits-Filho R, Figueiredo AE, Barretti P, de Moraes TP. Public health investments and mortality risk in Brazilian peritoneal dialysis patients. Clinical Kidney Journal, 13:1012-1016. 2020; doi: 10.1093/ckj/sfaa118.

20. Rodrigues KM, Cruz JAW, Vale RR, Moraes SC, Kato HT, Weymer ASQ. The effect of volunteer work in hospitals In Interdisciplinary Journal of Social Management a Brazilian University Hospital. 2021.

21. IBGE. Sociodemographic and health indicators in Brazil. 2009. https://biblioteca.ibge.gov.br/index.php/biblioteca-catalogo?view=detalhes\&id=283097. Accessed 05 July 2021.

22. Tuon FF, Pepes A, Oliveira DDS, Zequinão T, Cruz JAW, Telles JP. Cost-minimization in Health: linezolid versus vancomycin with serum monitoring in patients with incipient renal failure - a simulation and real-life. Brazilian Journal of Health Review, 4:17974-17987. Jul/Aug 2021. DOI: https://doi.org/10.34119/bjhrv4n4-275. 
23. Bromage DI, Cannatà A, Rind IA, Gregorio C, Piper S, Shah AM, McDonagh TA. The impact of COVID19 on heart failure hospitalization and management: report from a Heart Failure Unit in London during the peak of the pandemic. European Journal of Heart Failure, 22:978-984. 2020 Jun. doi: 10.1002/ejhf.1925. Epub 4 July 2020. PMID: 32478951; PMCID: PMC7300902.

24. Severino P, D’Amato A, Saglietto A, D'Ascenzo F, Marini C, Schiavone M, Ghionzoli N, Pirrotta F, Troiano F, Cannillo M, Mennuni M, Rognoni A, Rametta F, Galluzzo A, Agnes G, Infusino F, Pucci M, Lavalle C, Cacciotti L, Mather PJ, Grosso Marra W, Ugo F, Forleo G, Viecca M, Morici N, Patti G, De Ferrari GM, Palazzuoli A, Mancone M, Fedele F. Reduction in heart failure hospitalization rate during coronavirus disease 19 pandemic outbreak. ESC Heart Failure, 7:4182-4188. 2020 Oct 23. doi: 10.1002/ehf2.13043. Epub ahead of print. PMID: 33094929; PMCID: PMC7754919.

\section{Figures}



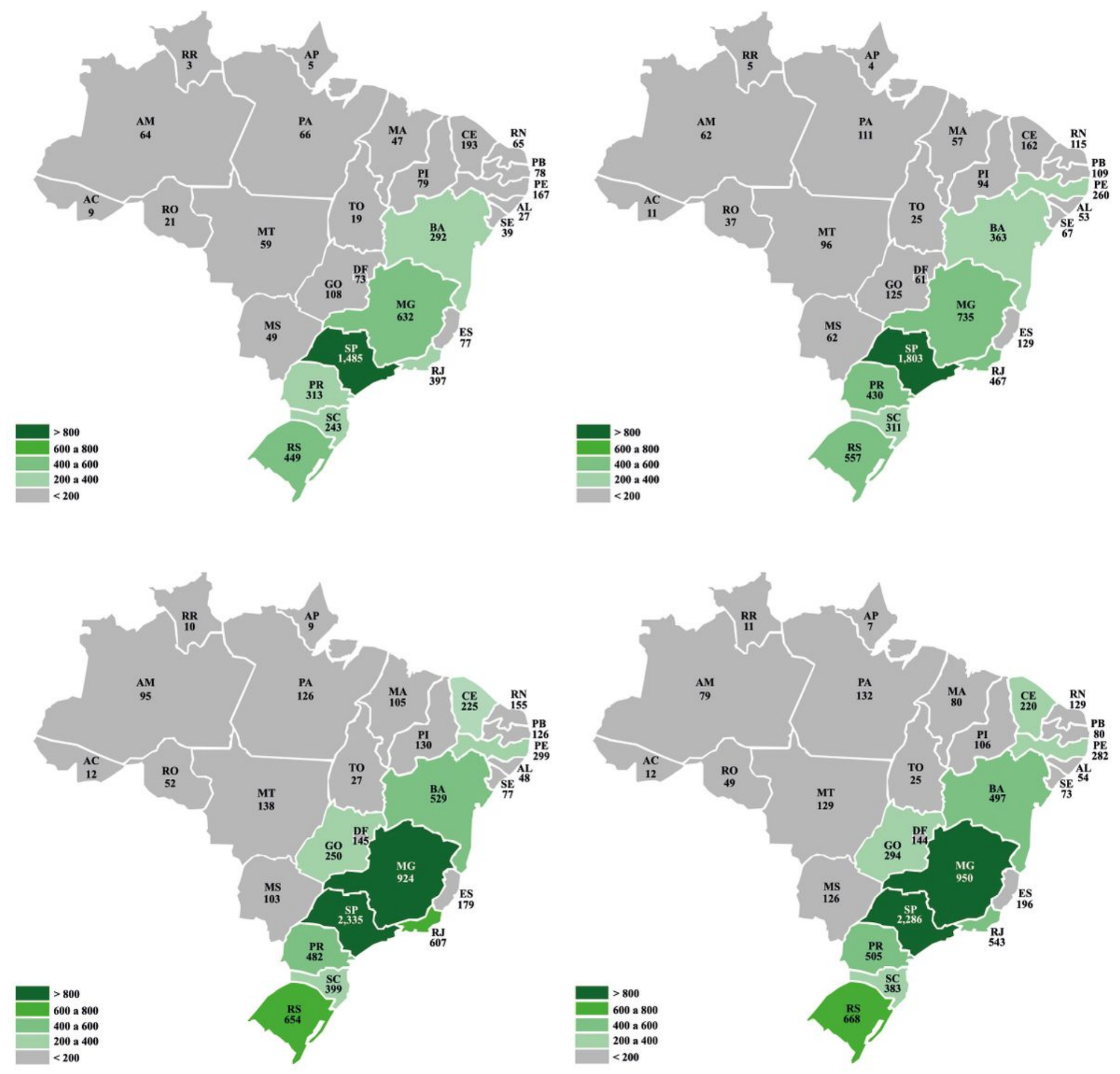

Figure 1

Map of Brazil with the number of hospital admissions of IAM per 100,000 inhabitants in 2011,2015 , 2019, and 2020. 


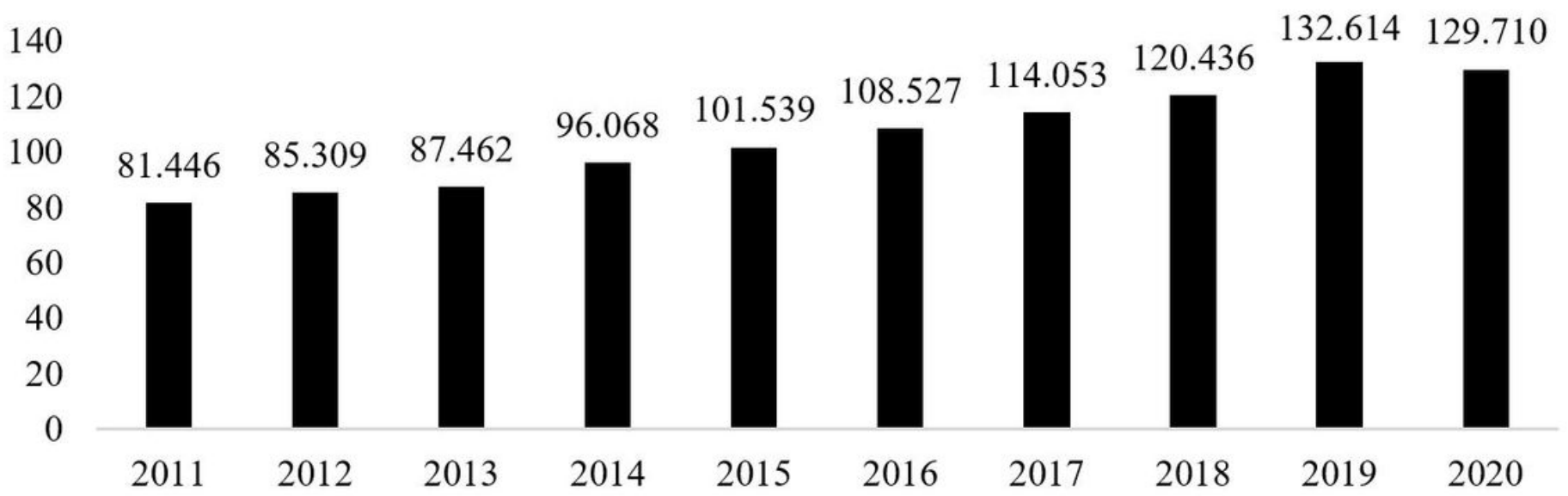

Figure 2

Historical series of IAM hospitalizations (2011 to April 2021)
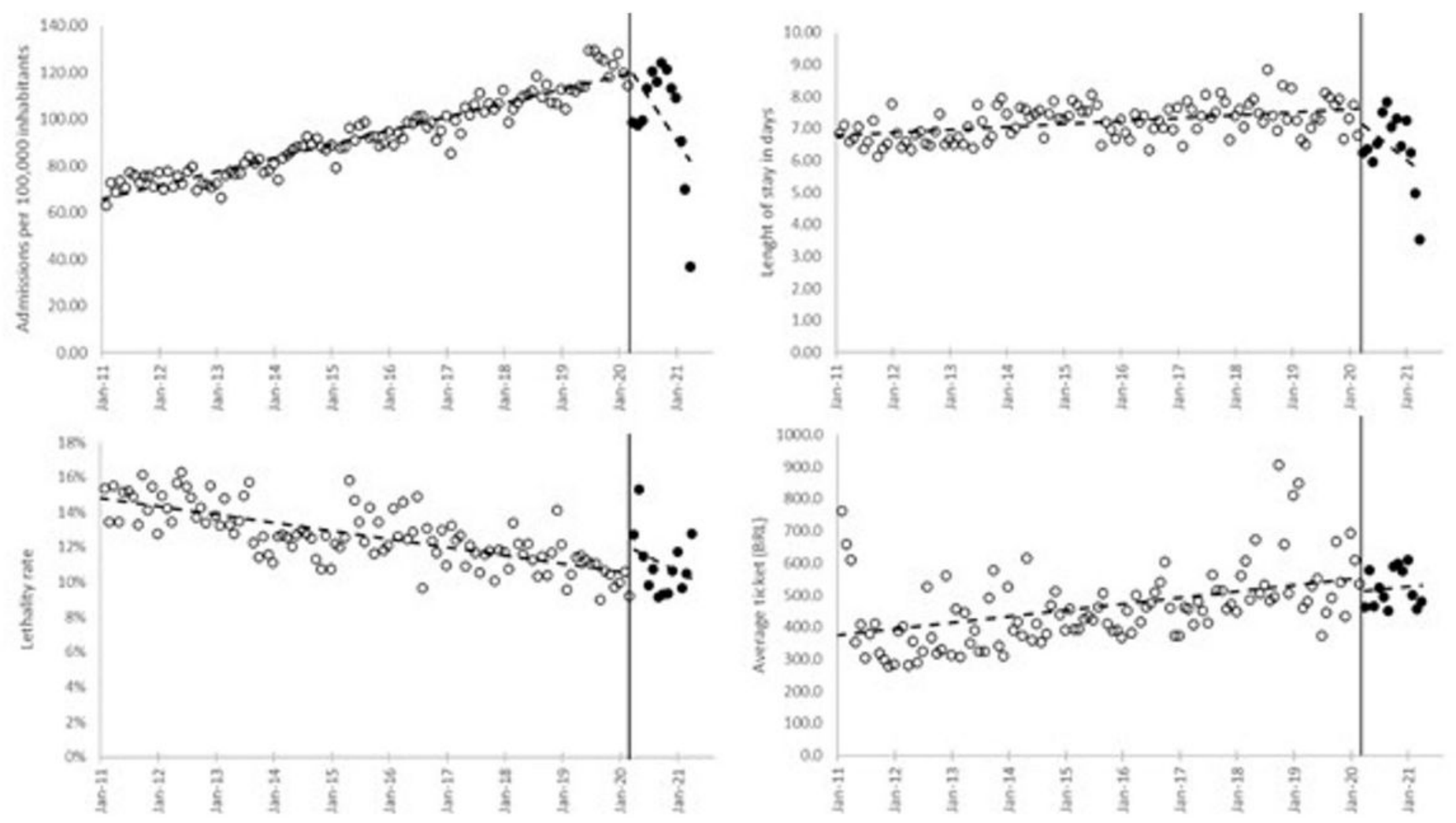

Figure 3

Monthly time series. 


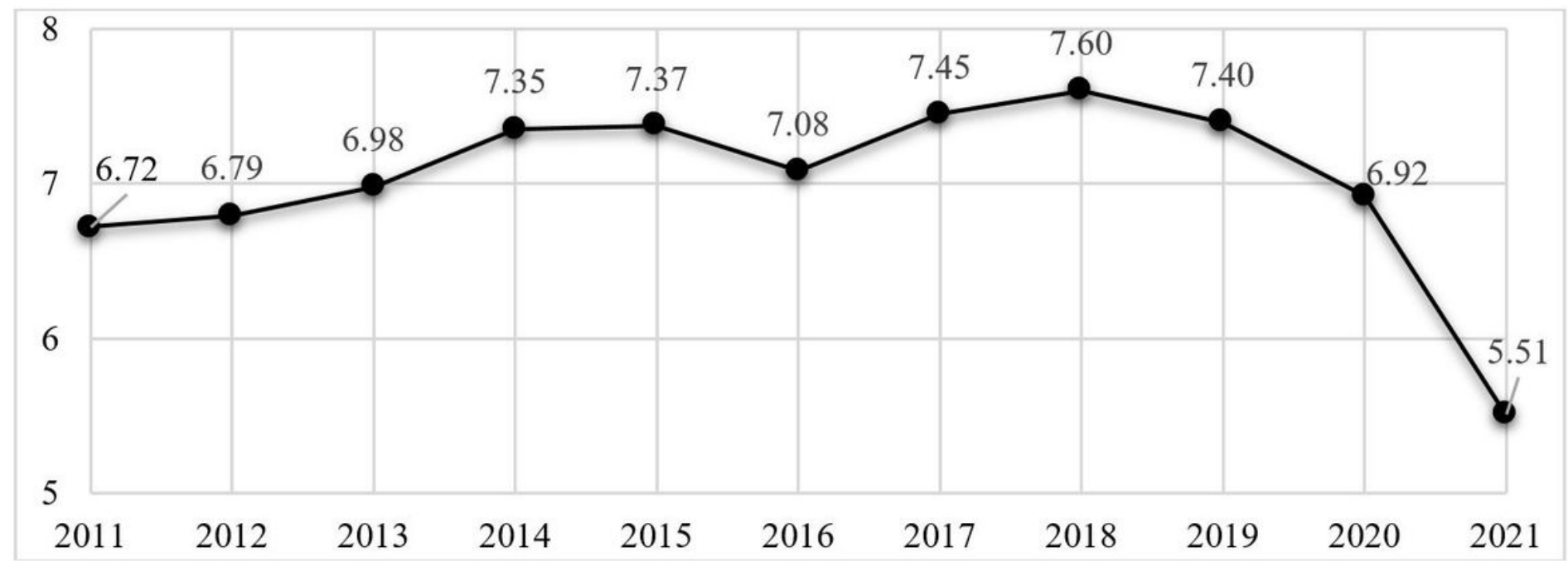

Figure 4

Historical series of average stay (year) from January 2011 to April 2021.

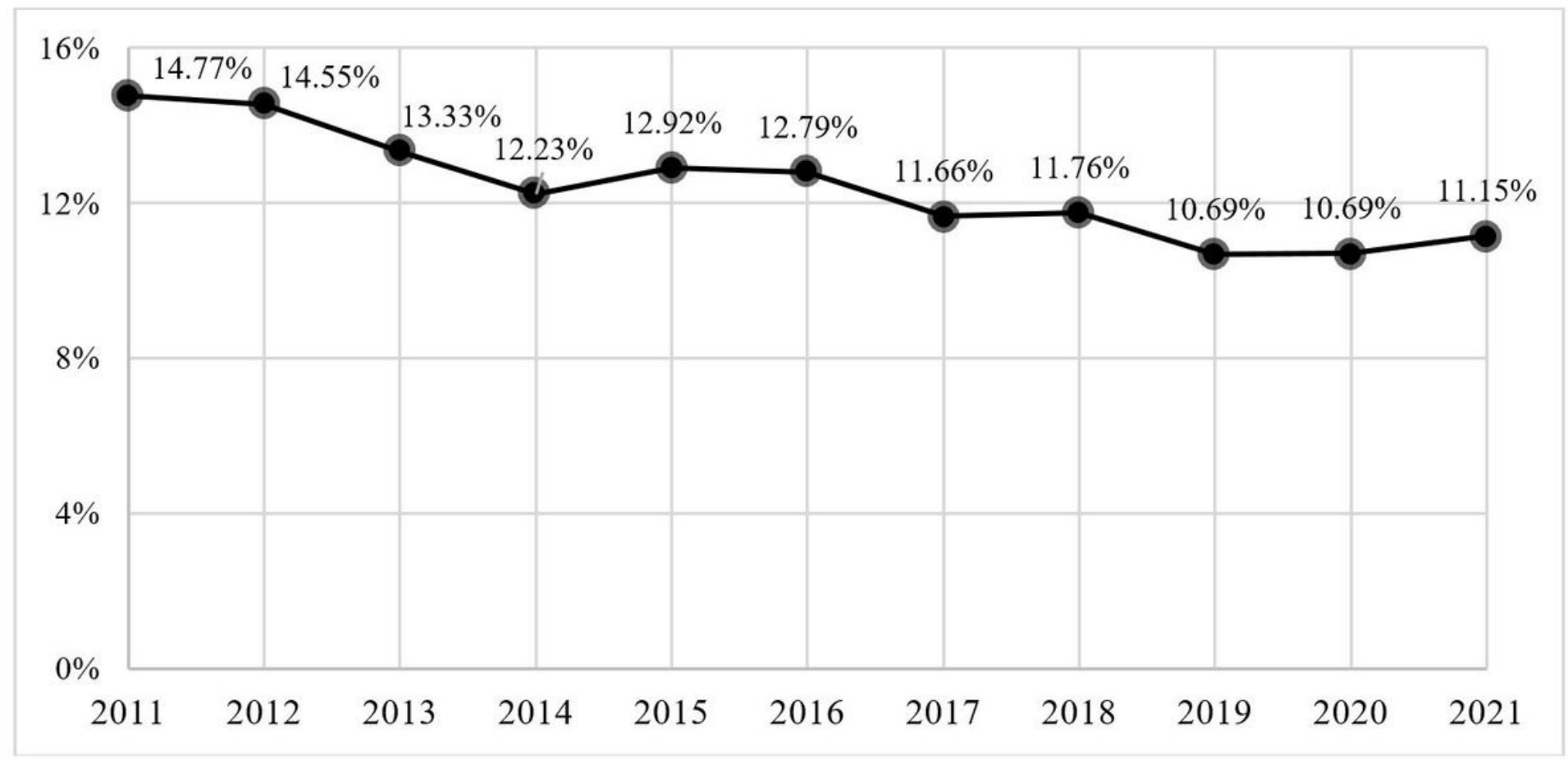

\section{Figure 5}

Historical series of IAM mortality from 2011 to April 2021 


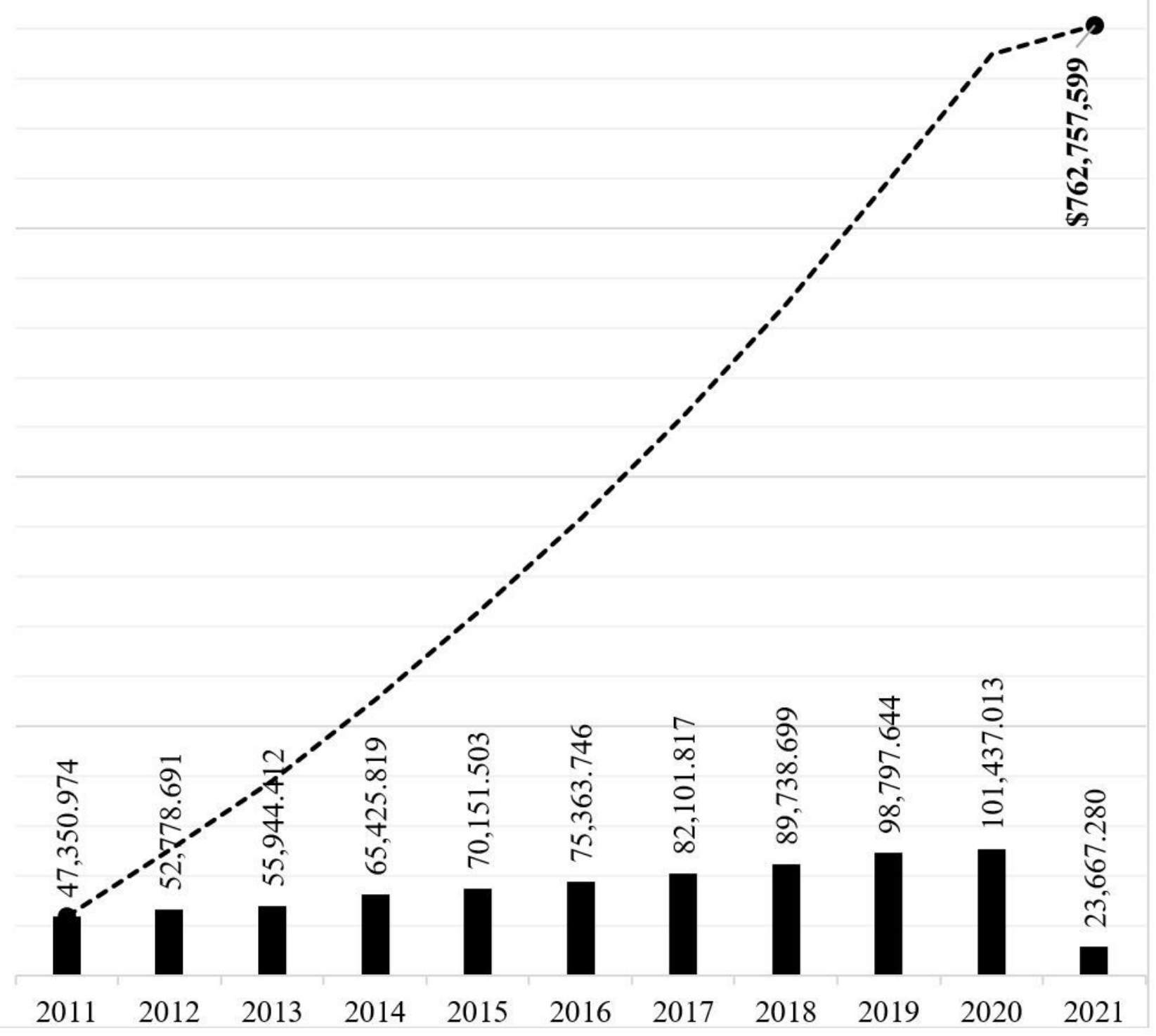

Figure 6

Historical series of payments linked to IAM from 2011 to April 2021. 


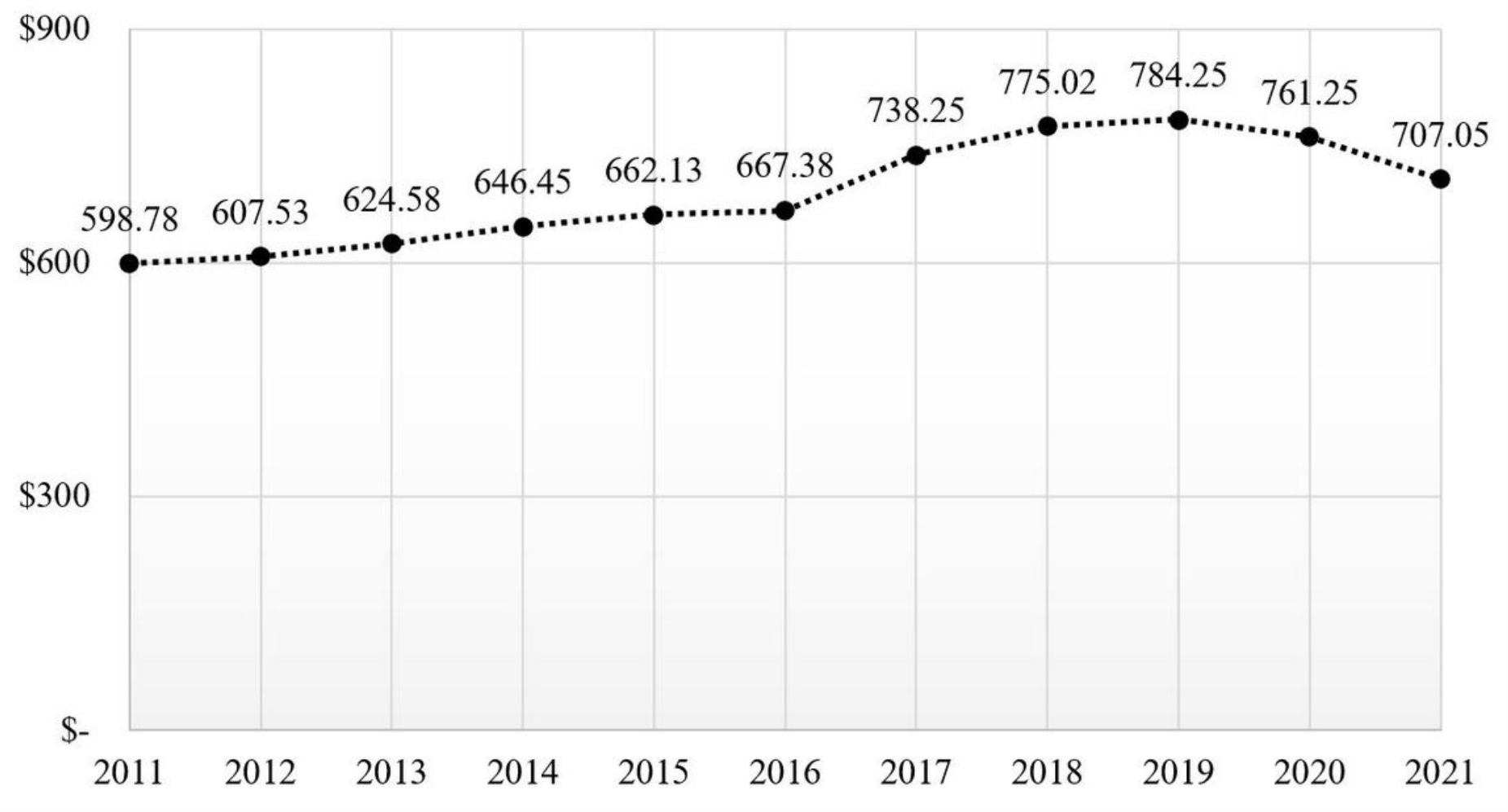

Figure 7

Historical series of average ticket linked to IAM from 2011 to April 2021.

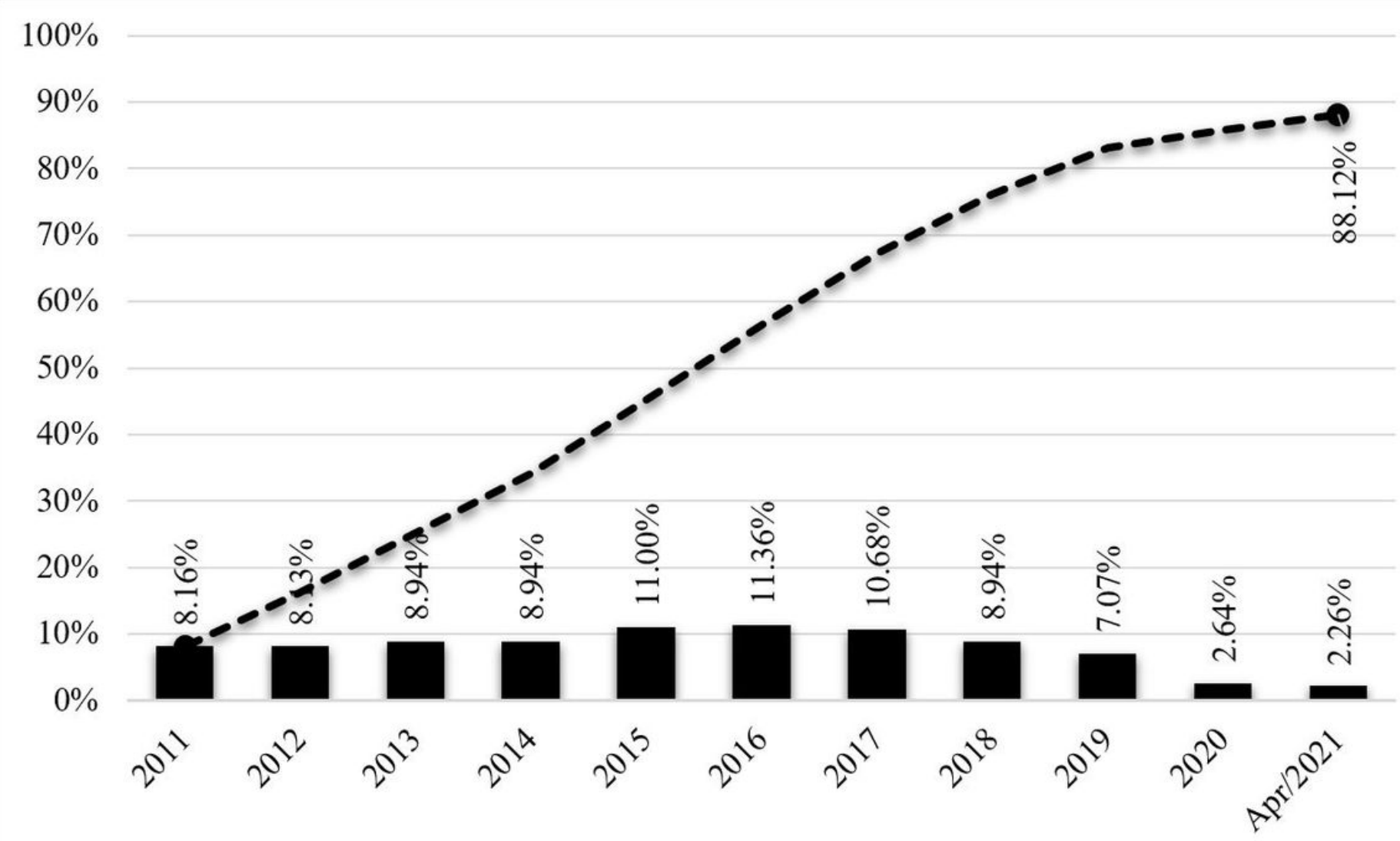


Figure 8

Historical series of price adjustment in Brazilian health (IPCA Saúde) from 2011 to April 2021

\section{Supplementary Files}

This is a list of supplementary files associated with this preprint. Click to download.

- AMIDataBaseFiguresTablesandGraphics.xIsx 